\title{
The Effect of Chants and Short Stories on Primary Stage Pupils' Communication and Attitudes
}

\author{
Mahmoud Kamal Ibrahim Mostafa \\ English Department, Faculty of Arts, Al-Baha University, Al-Baha, Saudi Arabia \\ Email address: \\ Mkim197587@gmail.com \\ To cite this article: \\ Mahmoud Kamal Ibrahim Mostafa. The Effect of Chants and Short Stories on Primary Stage Pupils' Communication and Attitudes. \\ International Journal of Elementary Education. Vol. 6, No. 4, 2017, pp. 38-41. doi: 10.11648/j.ijeedu.20170604.12
}

Received: April 21, 2017; Accepted: May 6, 2017; Published: October 19, 2017

\begin{abstract}
The aim of the study is to investigate the effectiveness of using and short stories in developing the third primary graders' English communicative skills in Damietta governmental schools. In order to answer the questions of the study, the researcher adopted the quasi-experimental approach. The sample of the study consisted of (50) pupils from Dr Ahmed Zwail primary school in New Damietta city. The chants/songs and short stories were used with the study group in the second term of the academic school year $(2014-2015)$. An oral communication test of six questions with (30) items was designed to be used as a pre -post test. The study indicated that there are statistically significant differences in mean scores of communicative skills test in favour of the post application. It also showed that there were statistically significant differences in mean scores of each of the communication skills in favour of the the post application. In the light of these results, the study recommended the necessity of using children chants/songs and short stories in teaching and learning. It also suggested that further researches should be conducted on the effect of songs and stories on the four skills of English language.
\end{abstract}

Keywords: Oral Communication Skills (OCS), Integrated Chants, Short Stories (ICS)

\section{Introduction}

The English language is a system of sounds and signs organised by grammatical rules of combination to communicate meaning successfully. Oral communication is the most important aspect of English language which is used to express thoughts, hopes, ambitions, and daily actions. Moreover, effective communication is an integral part of daily life, especially in education. It is the core of every aspect of interaction with others. According to Schady (2011) childhood period is the most rapid period of development in human life. Although individual children develop at their own pace, all children progress through an identifiable sequence of physical, cognitive, social and emotional growth and change.

Juraid, Ibrahim, Methods, \& Munawrah (2016) claim that the status of English as a global lingua franca has led to policy on primary English education in many non-English speaking countries. Teaching English in formal educational settings (e.g., primary schools) is a relatively new global phenomenon, and it started in Egypt in the 1990s. in addition, Thapa, Cohen, Guffey, \& Higgins D'Alessandro (2013) argue that pupils can learn literacy skills through instruction and practice of speaking, reading, writing and listening. Oral communication is the process exchanging information through the sense of hearing and making meaning from what was practised.

Jalongo (2008) assures that oral communication prepares young children for later better learning. This may be the reason why Raghavendra, Olsson, Sampson, Mcinerney, \& Connell (2012) submitted that it is crucial for a child to develop good communication skills in order to cope with the academic demands of school and to learn adequate literacy skills.

Communication skills help children to guide their selfinquiry and discover their individual possibilities. Children who are active communicators can incorporate the things they hear faster in their framework of knowledge than a more passive counterpart. In his own view, Tramel (2011) observed that Children can also exhibit better concentration and memory when they develop good communication.

Shiel, Cregan, McGough, \& Archer (2012) cited that oral 
communication is the child's first, most important, and most frequently used structured medium of communication. In addition, and most significantly, oral communication is the primary mediator of culture, the way in which children locate themselves in the world. Basically, oral communication is about communicating with other people. It involves a process of utilising knowledge and skills in order to speak and listen effectively.

Ferrari, Punie, \& Redecker (2012) assert that although the curriculum places a strong emphasis on oral communication, it has been widely acknowledged that the implementation of the Oral communication strand has proved challenging and there is evidence that some teachers may have struggled to implement this component because the underlying framework was unclear to them.

Children, as beginners, may face many communication problems. Salmon (2017) reveals that around half of children enter schools with a lack of communication ability. All those who have poor communication skills may face many difficulties relating to what is known as speech, language and communication needs (SLCN).

Lindsay, Dockrell, Desforges, Law, \& Peacey (2010) declare that the reasons for such difficulties are various. These include families with lower socioeconomic status, children with hearing loss, brain injury, learning disabilities and for some, the cause is unknown. After they have these difficulties, many children become silent, friendless, and feel lonely and easily rejected by classmates, when trying to make friends or join a group activity.

Zhang (2009) asserts that pupils who study English as a foreign language (EFL) usually have limited opportunities to communicate in English outside the classroom and also have limited exposure to English speakers or members of the international community. This might be one reason for teachers to provide more situations, activities and strategies for pupils to strengthen their oral communication performance.

In this respect, the researcher suggests that short stories and chants which can be one of those activities/strategies which encourage pupils to learn and practice English. Short stories are a form of oral communication which encourages young learners of English language and makes them active during the learning process. It is not a one-way act as there are usually at least two people involved, a teller and an audience, a listener or recipient. Also Forster (2006) assures that chants provide familiar things to children and create an active interaction amongst pupils through repetition and intonations. If there is a topic which is hard to explain to children, we can integrate the topic into a story or a chant. Stories and chants can present the introduction and solution which might help children to visualise the textbooks and understand the topic better.

Here is a sample of the chants and short stories followed by a teacher's guide written by the researcher. The researcher turned the content of TIME FOR ENGLISH series into chants and short stories. After applying these chants and short stories, pupils were amazingly inspired and encouraged to share and communicate in English during and out the class.

\section{Method and Procedures}

This chapter deals with all the research design, participants and instruments of the study. Also, it tackles the materials of the study, the experimental procedures and administration of the study instruments.

\subsection{Research Design}

The research adopted the quasi-experimental one group pre-posttest design. Children's songs and stories were used with the study group. By the end of the experiment, the communication pre-posttest was administrated to the study group in order to determine the effectiveness of children songs and short stories in developing pupils' communicative skills.

\subsection{Participants of the Study}

The participants of the study were 50 pupils enrolled in the third year, Dr Ahmed Zewail primary school, New Damietta city. They were aged 8-9 years old during 2014/2015 academic year. They were treated as one quasi-experimental group, having a pre-posttest before and after the experimental procedures.

\subsection{Variables of the Study}

The study included the following variables:

a. The independent variable is represented in the integrated chants/songs and short stories.

b. The dependent variable is represented in the development of the third graders' English communication skills.

\subsection{The Instruments and Materials of the Study}

The researcher used the following instruments:

a) An oral communication skills checklist.

b) An oral communication skills test.

c) A teacher's guide based on the integrated songs/chants and short stories.

\subsubsection{The Oral Communication Skills Checklist}

The checklist aimed to determine the oral communication skills necessary for $3^{\text {rd }}$ primary graders.

The checklist was constructed in the light of the following:

1. Reviewing previous studies concerned with EFL oral communication skills, especially those related to integrated songs/chants and short stories in teaching EFL in the primary stage.

2. Reviewing the syllabus directives of Time For English book of grade three.

3. Consulting supervisor's curriculum planners about what is suitable for the primary stage pupils.

The checklist relied on the $3^{\text {rd }}$-grade syllabus (Time For English) oral skills (listening and speaking). These oral communication skills (OCSs) were extracted from units 7 and 8 in addition to the literature MOE directives. The OCSs checklist contained the oral communication skills (listening 
and speaking).

Checklist validity

To validate the checklist, it was submitted to a panel of juries in curriculum and methods of teaching EFL. The juries were asked to evaluate the checklist in terms of clarity, readability and its suitability for $3^{\text {rd }}$-year pupils' communication skills.

The jury members validated the checklist items and their comments were modifying some items to suit $3^{\text {rd }}$ primary stage pupils such as $8,12,14,16$ and 19 items of the first version of the checklist (see appendix C).

\subsubsection{An Oral Communication Skills Pre-posttest}

It aims to determine the participants'(OCSs) level in their entry level as to oral communication skills before the test administration.

The oral communication skills test was constructed in the light of the following resources:

1. Reviewing the previous studies concerned with EFL tests, especially those related to communication skills.

2. Reviewing literature of teaching oral communication skills.

The oral communication skills pre-posttest consisted of 6 questions; two question for speaking skills, two questions for listening skills, one question for grammar and one question for vocabulary. Each question consisted of five items. So, the total items of the pre-posttest were 30 .

To validate the OCSs test, the researcher submitted the test to a panel of the jury who are specialised in curriculum and methods of teaching EFL. The jury members were asked to validate the test and judge the clarity of its questions and their suitability for the pupils' levels and what these questions aimed to measure. They were also asked to add, omit or modify any question(s) as they saw fit. According to the jury's remarks, modifications were made. The test in its final version was attached in the appendix (D).

The reliability of the test was computed using the test retest method before administrating the test to the participants of the study. It was administrated to 20 pupils on $3^{\text {rd }}$ November 2014. Four weeks later, on $30^{\text {th }}$ November 2014, the same test was applied to the same group under the same conditions. Then, the correlation coefficient between the first and the second administrations of the test was calculated using the correlation coefficient analysis as shown in tables (1) and (2). The reliability coefficient was 0.87 as shown in table (3) which was statistically significant at 0,001 , thereby reflecting test reliability

\subsubsection{Teacher's Guide}

The researcher prepared a teacher's guide to help and guide the teacher when teaching the proposed study.

So, the researcher prepared the teacher's guide determining the following:

a. The objectives of each lesson in the light of the cultural and linguistic content of these lessons.

b. The method of teaching songs/chants and short stories in the light of the suggested study.

c. The suitable aids to be used to help pupils during learning.

d. The suitable activities and practice to evaluate the pupils' performance of each lesson according to its nature and according to pupils' needs and objectives of the lessons.

The sources of the teacher's guide are the researcher's experience as and an English teacher. Moreover, English supervisors' experience and some of English teachers' experience in Dr Ahmed Zwail primary school.

The teacher's guide includes information about applying the experiment. It includes the objectives and procedures of the lessons. The researcher suggests a lesson plan that is a model for using children songs/chants and short stories in practising oral communicative skills. The lesson plan includes the learning objective, sources, procedures for presenting songs/chants and short stories and practice.

A panel of language and EFL instruction specialists, some of English teachers and English language supervisors shared in revising the teacher's guide. The researcher made some modifications to make the teacher's book valid.

The content of the teacher's guide depended on primary three books to apply the study. The researcher analysed the content of the school book to know the information included, integrated the song/chants and stories which contain each lesson's information and designed the suitable activities that were used through the application.

The determined content consisted of two units (the first two units of the second term), each unit consisted of 4 lessons (total of 10 lessons, besides the first two lessons in which the researcher agreed on the procedures of applying the suggested study with the subjects. The following table shows the analysis of the content.

\section{Conclusions}

The outcome of this study substantiates an initial belief regarding the fact that the study group learners were able to comprehend the integrated chants/songs and short stories and provide a fluent oral communication skills. In fact, even though the learners started from a slightly lower level of English, they improved their oral communication skills (listening and speaking) and performed the songs and short stories successfully.

However, in order to obtain better results, the researcher believes that there is an urgent need to develop new materials and resources adapted to non-native young learners. If the existent materials are to be used in the EFL classroom, and just to mention some of the paths to explore, they need to include higher quality sound, chants/songs and slower storytelling pace. Graded pedagogical tasks responding to the learners' age and developmental stage would also be necessary.

Finally, suitable chants and short stories for children are needed, both from a cognitive and communicative perspective, and, perhaps more importantly, to ensure their relation to the syllabus and the nature of children. 


\section{References}

[1] Ferrari, A., Punie, Y., \& Redecker, C. (2012). Understanding Digital Competence in the 21st Century: An Analysis of Current Frameworks. In 21 st Century Learning for 21st Century Skills (pp. 79-92). Springer. https://doi.org/10.2791/82116

[2] Forster, E. (2006). The value of songs and chants for young learners.

[3] Jalongo, M. R. (2008). Beyond a pets theme: Teaching young children to interact safely with dogs. Early Childhood Education Journal, 36 (1), 39-45.

[4] Juraid, R. A., Ibrahim, M. M. A., Methods, T., \& Munawrah, M. (2016). THE EFFECT OF STORYTELLING ON DEVELOPING COMMUNICATION SKILLS OF EFL FEMALE STUDENTS AND THEIR ATTITUDES TOWARDS IT, 5 (November).

International Journal of Language \& Communication Disorders, 45 (4), 448-460.

[6] Raghavendra, P., Olsson, C., Sampson, J., Mcinerney, R., \& Connell, T. (2012). School participation and social networks of children with complex communication needs, physical disabilities, and typically developing peers. Augmentative and Alternative Communication, 28 (1), 33-43.

[7] Salmon, C. (2017). Storytelling: bewitching the modern mind. Verso Books. Schady, N. (2011). Parents' education, mothers' vocabulary, and cognitive development in early childhood: Longitudinal evidence from Ecuador. American Journal of Public Health, 101 (12), 2299-2307.

[8] Shiel, G., Cregan, Á., McGough, A., \& Archer, P. (2012). Oral language in early childhood and primary education (3-8 years). Dublin: National Council for.

[9] Thapa, A., Cohen, J., Guffey, S., \& Higgins-D’Alessandro, A. (2013). A review of school climate research. Review of Educational Research, 83 (3), 357-385.

[5] Lindsay, G., Dockrell, J., Desforges, M., Law, J., \& Peacey, N. (2010). Meeting the needs of children and young people with speech, language and communication difficulties.

[10] Zhang, Y. (2009). Reading to Speak: Integrating Oral Communication Skills. English Teaching Forum. Retrieved from http://eric.ed.gov/?id=EJ923446 